\title{
MIDAS
}

Museus e estudos interdisciplinares

\section{Património cultural e discursos museológicos: narrativas de memórias e identidades locais}

cultural heritage and museum discourse: memories of narratives and local identities

\section{Atila Bezerra Tolentino}

\section{OpenEdition}

\section{Journals}

\section{Edição electrónica}

URL: http://journals.openedition.org/midas/1012

DOI: 10.4000/midas.1012

ISSN: 2182-9543

\section{Editora:}

Alice Semedo, Paulo Simões Rodrigues, Pedro Casaleiro, Raquel Henriques da Silva, Ana Carvalho

\section{Refêrencia eletrónica}

Atila Bezerra Tolentino, «Património cultural e discursos museológicos: narrativas de memórias e identidades locais », MIDAS [Online], 6 | 2016, posto online no dia 24 março 2016, consultado no dia 19 abril 2019. URL : http://journals.openedition.org/midas/1012 ; DOI : 10.4000/midas.1012

\section{Este documento foi criado de forma automática no dia 19 Abril 2019.}

\section{c) (i) (2)}

Midas is licensed under a Creative Commons Attribution-NonCommercial-ShareAlike 3.0 International License 


\section{Património cultural e discursos} museológicos: narrativas de memórias e identidades locais

Cultural heritage and museum discourse: memories of narratives and local identities

Atila Bezerra Tolentino

NOTA DO EDITOR

Artigo recebido a 04.02.2015

Aprovado para publicação a 21.12.2015 


\section{Museus: entre a resistência e a apropriação}

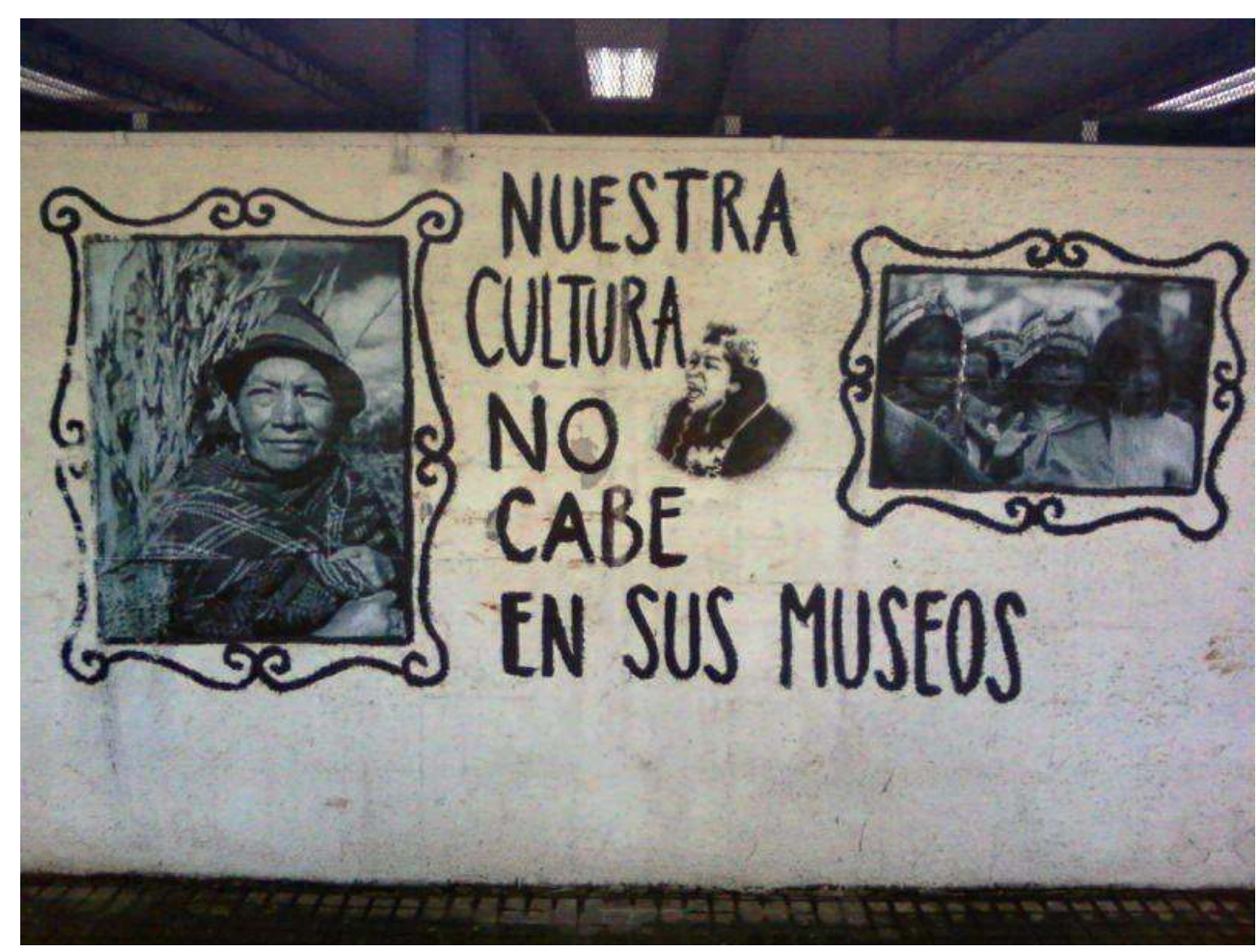

Fig. 1 - Imagem amplamente difundida na internet, demonstrando a resistência cultural dos índios Mapuche do Chile e da Argentina

Autoria desconhecida

O espírito da dança, chamado klassila, ficou preso nos cárceres de Ottawa, durante muitos anos, e estava sendo devolvido agora ao povo kwagiulth. O poder do espírito tinha sido, simbolicamente, jogado fora do barco, no litoral, mas foi "pescado" e aquele que o incorporou começou a dançar. Depois, arremessou-o energicamente à praia, fazendo-o transpor as portas do museu. 0 espírito, enfim, conseguiu entrar na morada sagrada: o museu. (Assu 1989, citado por Clifford 2003, 301)

1 A citação acima, que trazemos para abrir este artigo, foi utilizada por Clifford (2003) para encerrar as suas reflexões no texto Museologia e Contra-história: Viagens pela Costa Noroeste dos Estados Unidos. A citação é do chefe da aldeia de Cape Mudge, Harry Assu, localizada na Ilha de Quadra, da costa leste de Vancouver (Canadá) e faz parte das suas memórias, publicadas em livro, aquando da abertura do Museu e Centro Cultural Kwagiulth, na sua aldeia em 1979. A criação deste museu tribal, esclarece Clifford, deu-se como exigência de repatriação de objetos da festa cerimonial polatch, confiscados pelo Governo canadiano nos anos de 1920. Essa festa, de caráter sagrado, era promovida por grupos indígenas da costa norte do Pacífico e, durante muitos anos, foi proibida pela Igreja e pelo Estado. A citação remete para a ideia de que um museu, mesmo imposto e considerado como uma instituição extremamente elitista, pode ser recomeçada e reinventada. As palavras do chefe da aldeia de Cape Mudge servem de inspiração para que possamos fazer uma relação com a imagem que também abre este artigo (fig. 1). Na imagem lê-se: «A nossa cultura não cabe nos vossos museus», foi amplamente difundida na internet e nas redes sociais, servindo como referência de resistência cultural e de denúncia da incapacidade ou limitação de instituições culturais como os museus, recorrentemente elitistas e 
sacralizadas, de serem espaços representativos da diversidade cultural e de diferentes narrativas identitárias.

Como símbolo de resistência, a imagem (fig. 1) refere-se aos índios Mapuche, povo originário que habita o sul do Chile e sudoeste da Argentina. Os Mapuches têm uma história de luta pelas suas terras e cultura desde a época colonial hispânica. No final do século XIX, os Estados argentino e chileno ocuparam os seus territórios por via de operações militares, chamadas de Conquista do Deserto e Pacificação da Auracanía. Atualmente, vivem um intenso processo de defesa pela sua identidade, frente a uma sociedade excludente e dominante, através da resistência cultural ${ }^{1}$ e luta pelo reconhecimento de direitos e pela recuperação de sua autonomia. Barrera (2006), ao analisar o discurso poético Mapuche, destaca que, nessa luta, os escritos Mapuches procuram construir sujeitos ontologicamente estáveis sob as premissas de uma universalidade dos sujeitos modernos. Reivindicam a sua própria existência no complexo cenário de representações, como resposta aos emergentes discursos que fundamentam a diferença étnica, cultural, de género, entre outras, e que procuram legitimar não somente as vozes, mas também posicionar as visões relegadas por uma história oficial.

3 Entre a resistência dos índios Mapuche e a abertura dos povos da aldeia de Cape Mudge à instituição museológica, inúmeras considerações e reflexões sobre o campo dos museus, da museologia e do património cultural podem ser traçadas, trazendo a discussão para a realidade brasileira e, mais especificadamente, para o campo dos museus comunitários e ecomuseus, assunto bastante caro à linha de pensamento hoje denominada de museologia social ou sociomuseologia. Os museus, surgidos inicialmente como gabinetes de curiosidades por meio de coleções principescas, atrelaram-se à formação dos Estados nacionais, multiplicaram-se, foram presumidamente fadados à morte, ganharam novos contornos, reinventaram-se e, atualmente, vivem uma verdadeira «museodiversidade» (Chagas 2009) tanto no Brasil, como no estrangeiro.

4 Nesta reflexão tomamos como exemplo as práticas sociais de preservação e valorização das referências culturais das comunidades rurais e urbanas do Vale do Gramame, localizadas nas proximidades da região dos rios Gramame e Jacoca, nas cidades de João Pessoa e Conde, no Estado de Paraíba (Brasil). A partir da atuação do Museu da Escola Viva Olho do Tempo - EVOT (daqui em diante Museu Comunitário da EVOT) procuramos identificar e refletir de que forma a diversidade cultural e as memórias coletivas dessas comunidades são representadas nas suas práticas preservacionistas e como são construídas as narrativas discursivas do museu comunitário instituído na Escola. Ao compreender que o campo do património cultural se constitui como um espaço social de disputa política, económica e simbólica, levo em consideração discussões já travadas por autores que tratam o património cultural como categoria do pensamento (Gonçalves 2003; Chagas 2009; García Canclini 1997, 1999; Abreu 2007). Procuramos, também, situar a discussão a partir das questões apontadas por Hall $(2003,2011)$ a respeito da construção de identidades culturais na modernidade. E consideramos ainda as perspetivas da construção das memórias como um elemento social, a partir de Halbwachs (2006) e Ricouer (2007), bem como as relações de força que envolvem a conceção de capital simbólico, como proposto por Bourdieu (2005), no jogo dos conflitos sociais em torno do processo de seleção e na construção dos patrimónios culturais e da constituição de memórias coletivas.

5 Além da pesquisa bibliográfica, foi utilizada a técnica de observação participante, na esteira do que propõe Whyte (1980), durante o trabalho de campo. Para tal foram 
realizadas entrevistas e participámos em atividades e eventos promovidos pela EVOT. Realizámos igualmente pesquisa nos arquivos documentais e audiovisuais da instituição durante 2014 e 2015. A finalidade foi conhecer o modo de vida dessas pessoas, as relações que constroem com o lugar onde vivem e a participação de determinados atores nas lutas sociais coordenadas e encabeçadas pelo museu, permitindo a observação e a recolha de dados.

\section{A poesia do Museu Comunitário da Escola Viva Olho do Tempo}

6 García Canclini (1997), na sua obra Culturas Hibridas, expõe que, nos processos sociais, as relações altamente ritualizadas com um único e excludente património histórico nacional ou regional - dificultam o desempenho em situações mutáveis, as aprendizagens autónomas e a produção de inovações. 0 tradicionalismo substancialista incapacita para viver no mundo contemporâneo, que se caracteriza pela heterogeneidade, mobilidade e desterritorialização. As últimas ditaduras latino-americanas acompanharam a restauração da ordem social intensificando a celebração dos acontecimentos e símbolos que os representam: a comemoração do passado "legítimo", daquele que corresponde à "essência nacional", à moral, à religião e à família. Participar da vida social é agir de acordo com um sistema de práticas ritualizadas que deixam de fora o "estrangeiro", o que desafia a ordem consagrada e o ceticismo.

O museu, continua García Canclini (1997), é a sede cerimonial do património, o lugar onde é guardado e celebrado, onde se reproduz o regime semiótico com que os grupos hegemónicos o organizaram: é um palco-depósito que o contém e um palco-vitrine que o exibe. Entrar num museu não é simplesmente adentrar um edifício e olhar as suas obras, mas também penetrar num sistema ritualizado de ação social. Inúmeros museus, instituídos em regimes totalitários, são assim caraterizados, e procuraram ser representativos da nação, constituídos de um discurso homogeneizante da sociedade, ao mesmo tempo excludente e de acordo com uma historiografia oficial que não leva em conta as vozes dos distintos atores sociais. Mas o autor também adverte que os museus, como meios de comunicação de massa, podem desempenhar um papel significativo na democratização da cultura e na mudança do conceito de cultura. As mudanças na conceção do museu impedem-nos de continuar a entender estas instituições como simples depósitos do passado.

8 Nessa perspetiva, cabe apresentar a experiência das práticas preservacionistas e de valorização dos seus patrimónios culturais implementada pelas comunidades rurais e urbanas do Vale do Gramame, em João Pessoa e Conde, cidades da Paraíba, incluindo a criação e implantação do Museu Comunitário da EVOT. Nesta trajetória, cumpre delinear como foram construídas, no tecido social desses grupos, as representações das suas memórias e identidades coletivas, por meio da narrativa discursiva da exposição do museu.

O Vale do Gramame situa-se nas margens dos rios Gramame e Jacoca. A área rural é formada pelas comunidades de Engenho Velho, Gramame e Ponta do Gramame, em João Pessoa, e Mituaçu, comunidade quilombola e indígena no município do Conde. Devido à expansão imobiliária, já conta também com uma parcela de população urbana, com as comunidades Colinas do Sul I e II, Gervásio Maia e Conjunto Marinês, recentes bairros 
populares resultantes de políticas públicas de habitação. Entre as expressões culturais existentes nessa região banhada pelas águas dos rios, podem ser destacados o coco, a ciranda, a capoeira, a poesia popular, a lapinha, a quadrilha junina, a pesca artesanal, o forró pé-de-serra, o cultivo e manuseio de ervas, além de narrativas lendárias. É, portanto, uma região rica em recursos naturais e com grande vivacidade cultural (Tolentino 2014).

O Museu Comunitário faz parte da Congregação Holística da Paraíba - Escola Viva Olho do Tempo - EVOT, criada em 1998 como instituição social sem fins lucrativos. ${ }^{2}$ Na região do Vale do Gramame, desenvolve, desde 2004, projetos e atividades na área da educação não formal, da cultura e do meio ambiente, através de ações compartilhadas com a comunidade local e promovendo a convivência entre gerações. Pretende a valorização das culturas e das identidades locais.

11 O Museu Comunitário da EVOT foi criado no mês de maio de 2010, com uma exposição de objetos do quotidiano da comunidade relacionados com a pesca e o trabalho rural. Havia também uma exposição de fotografias e imagens das atividades desenvolvidas pela escola e das manifestações culturais locais. No ano de 2013, a exposição do museu foi reconfigurada, por meio de uma parceria com a Superintendência do Instituto do Patrimônio Histórico e Artístico Nacional (IPHAN) na Paraíba, montando-se um novo circuito expositivo, intitulado Vale do Gramame: Memórias e Vivências, em que se procurou mostrar as referências culturais da região e os problemas causados pela poluição dos rios, a partir do olhar dos mestres de cultura popular locais.

Antes de avançar na descrição de como este museu foi constituído, importa salientar que uma das acepções referentes à origem do termo "museu" remete-o para um lugar ao mesmo tempo de memória e de poder. 0 termo museu veio da palavra mouseion, que era o templo das musas, na Grécia antiga. As nove musas, protetoras das artes e da história, eram filhas de Zeus, deus supremo e todo poderoso, e de Mnemosine, deusa da memória ou das reminiscências. Portanto, mouseion era o templo ou herdeiro do poder e da memória. Esta relação do museu não só como um espaço de memória, mas sobretudo como um espaço de poder e como reflexo e resultado dos distintos atores sociais que o constroem e reconstroem, é bastante explorada pelo poeta e museólogo Mário Chagas (2009). Ao compreender os museus como «microcosmos sociais», Chagas reconhece os múltiplos significados que os objetos museais podem ter e, por conseguinte, como podem ser utilizados para construir diferentes discursos representativos das memórias e das identidades dos grupos sociais. É nessa perspetiva que Chagas procura «olhar não apenas para o litoral dos museus, ou seja, para a sua bela face de contato com o público, mas também para o seu sertão, para as correntes de forças e ideias que se movimentam em seus intestinos» (Chagas 2009, p. 24). Olhar os museus a partir do sertão é compreendê-los de forma crítica, é analisar como os sujeitos sociais estão ali representados e verificar de que forma os discursos museológicos foram construídos e como estão sendo apropriados pelo público.

13 Gonçalves $(2007,83)$ afirma que «os museus têm sido associados, nas modernas sociedades ocidentais, aos espaços de 'cultura letrada', da 'alta cultura' ou da 'cultura erudita', por oposição às 'culturas populares' ou à 'cultura de massa'». Mas também acrescenta: «As relações entre esse espaço nobre e as demais formas de cultura, no entanto, vêm sendo progressivamente desestabilizadas e suas fronteiras demarcatórias aparentemente enfraquecidas» (Gonçalves 2007, 83-84). Uma grande contribuição neste sentido foi dada pelo Movimento Internacional para uma Nova Museologia - MINOM, que se organizou na 
década de 1980, fortemente influenciado pela Mesa-Redonda de Santiago do Chile, encontro realizado em 1972, com o objetivo de debater o papel dos museus na América Latina, frente às transformações sociais, económicas e culturais, sobretudo nas regiões em via de desenvolvimento. Entre outros aspectos considerados importantes, foi ressaltado o papel do museu como uma instituição a serviço da sociedade, da qual é parte integrante e que possui os elementos que lhe permitem participar na formação da consciência das comunidades que serve. Ademais, foi reforçado que o museu pode contribuir para o engajamento dessas comunidades na ação frente aos problemas atuais, envolvendo-se nas mudanças de estrutura em curso e provocando outras mudanças no interior de suas respectivas realidades. É nesse contexto que se situa o Museu Comunitário da EVOT ${ }^{3}$.

$\mathrm{Na}$ sua primeira formatação, a exposição do museu resultou da recolha, junto das comunidades, de objetos que tivessem "significado", bem como a partir dos registos efetuados pela EVOT, que pudessem demonstrar as referências culturais e narrar as "histórias" do Vale do Gramame. Nessa exposição, exibiam-se objetos do quotidiano local, como artefatos dos saberes e fazeres dos mestres e peças de artesanato, além de farto material que resultou dos registos fotográficos das atividades desenvolvidas pela Escola nas comunidades, como a promoção do São João Rural, do Encontro Cultural "O Vale vai à Praça”, rodas de leituras com as crianças e mestres, entre outras. Como peça de destaque, foi construído um fogão de barro, muito comum na região, de modo a demonstrar uma típica cozinha rural, encontrada em muitas casas na localidade.

15 Como é bastante comum nos museus comunitários, essa primeira exposição não primava pelas técnicas expositivas ensinadas pela museologia, contendo visíveis problemas de comunicação e de seleção dos objetos expostos. No entanto, cabe considerar que na exposição, encabeçada de forma amadora (e aqui referimo-nos a dois aspectos significativos do termo amador, no sentido de não detentor de conhecimento técnico, mas também de amante, imbuído de amor) por membros das comunidades do Vale do Gramame, mais do que técnicas expositivas adequadas, o que vale é o desejo de memória de determinados atores sociais que estão nos limiares das identidades de resistências (Castells 2008) e a sua representação no discurso expositivo no museu, uma instituição na qual não se vêem comummente representados.

16 Entre 2012 e 2013, com o apoio da Superintendência do IPHAN no Estado de Paraíba, a exposição do Museu Comunitário da EVOT passou por um processo de requalificação, com vista à adoção de técnicas e materiais expositivos adequados à exposição dos objetos coletados e à produção dos conteúdos de comunicação. Procurou-se também construir, de forma participativa, uma narrativa que desse conta, dentro das limitações físicas e espaciais, de representar as memórias e as identidades das comunidades do Vale do Gramame, pautadas pelas suas referências culturais. Seguindo a linha de atuação da Escola nos seus trabalhos de memória, foi decidido que a exposição iria abordar as referências culturais da região a partir do olhar e das memórias dos mestres e mestras de cultura popular locais. Para o efeito, foram selecionados dez mestres que, de uma certa forma, tinham reconhecimento na localidade em função dos seus ofícios, dos seus saberes ou das manifestações culturais que promoviam.

17 A requalificação do museu deu-se como um processo e como produto de uma construção sociohistórica dos sujeitos sociais que dele participaram. O juntar coisas ou objetos referenciais das suas vivências para serem expostos esteve aliado a um processo de registo das memórias e vivências, em rodas de conversas com mestres e mestras de cultura popular locais e nas atividades desenvolvidas pela escola. A metodologia, 
explicitada de forma simplificada, demonstra uma finalidade: a valorização da identidade do indivíduo, enquanto sujeito inserido socialmente no seu grupo. Esse movimento de criação do museu leva em consideração que as ações museológicas consideram como ponto de partida a prática social e não somente as coleções ("coisas" coletadas).

Na nova exposição há uma parede na qual se destacam os mestres de cultura popular locais, que foram entrevistados para desenhar a nova expografia (fig. 2). Para cada um deles foram destinados três painéis. Na parte de cima, há uma imagem do próprio mestre. No meio, é apresentado um breve texto e um trecho do testemunho de cada um deles, recolhido durante as conversas para a preparação da exposição. Abaixo, os painéis apresentam uma imagem do ofício que cada mestre exerce ou da manifestação cultural que promovem. Na ordem em que se apresentam, da esquerda para a direita, os mestres são: Betinha, cantadora de Lapinha; Zé Pequeno, mateiro e pescador; Zé do Balaio, artesão, que trabalha com cipó titara; Judite Palhano, poeta popular; João, Ciça e Geralda, cirandeiros; Zominho, tocador de acordeão; Marcos, puxador de quadrilha; e Doce, contadora de histórias.

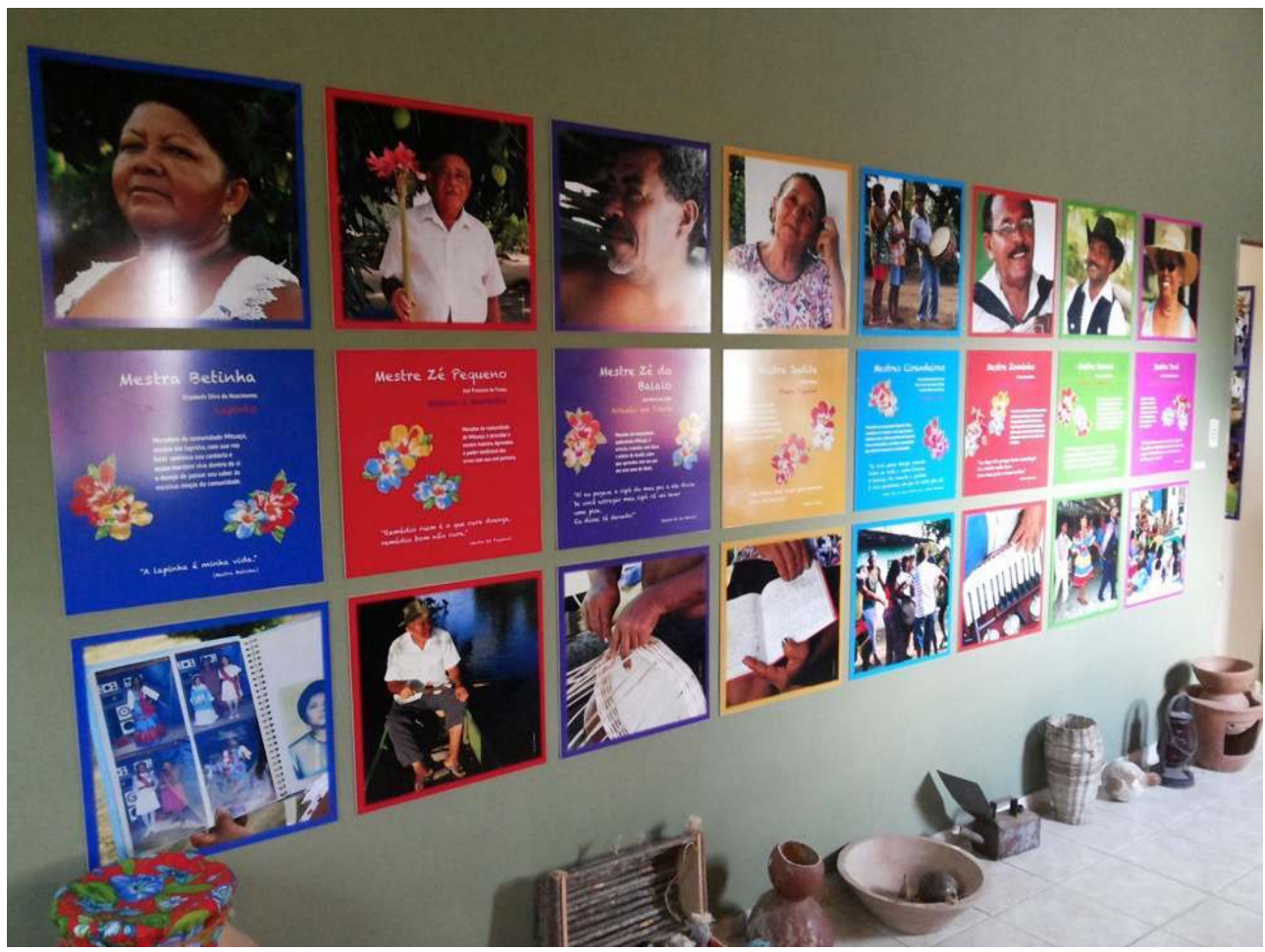

Fig. 2 - Painéis representando os mestres do Vale do Gramame

(c) Atila Bezerra Tolentino

Poderíamos afirmar que o rio Gramame é o grande personagem na exposição. Um barco, centralizado numa das salas, traz no seu interior apetrechos e instrumentos de pesca (tarrafa, samburá, cova, ratoeira, remos, candeeiro, balaios, gereré, etc), remetendo para o universo ribeirinho local (fig. 3). Como é comum nos barcos construídos pelos mestres barqueiros, há uma frase escrita na zona lateral do barco. Nesse barco, a frase instiga o visitante a refletir sobre um problema social peculiar a muitas comunidades ribeirinhas e extremamente atual para os moradores do Vale do Gramame: «O Velho Gramame quer viver em águas limpas», denunciando a poluição do rio, em função das inúmeras fábricas e indústrias instaladas em seu redor, que deitam os seus dejetos no leito dos rios. A frase 
do barco é complementada com o trecho de uma poesia da mestra Judite Palhano, inscrita num dos painéis sobre o rio:

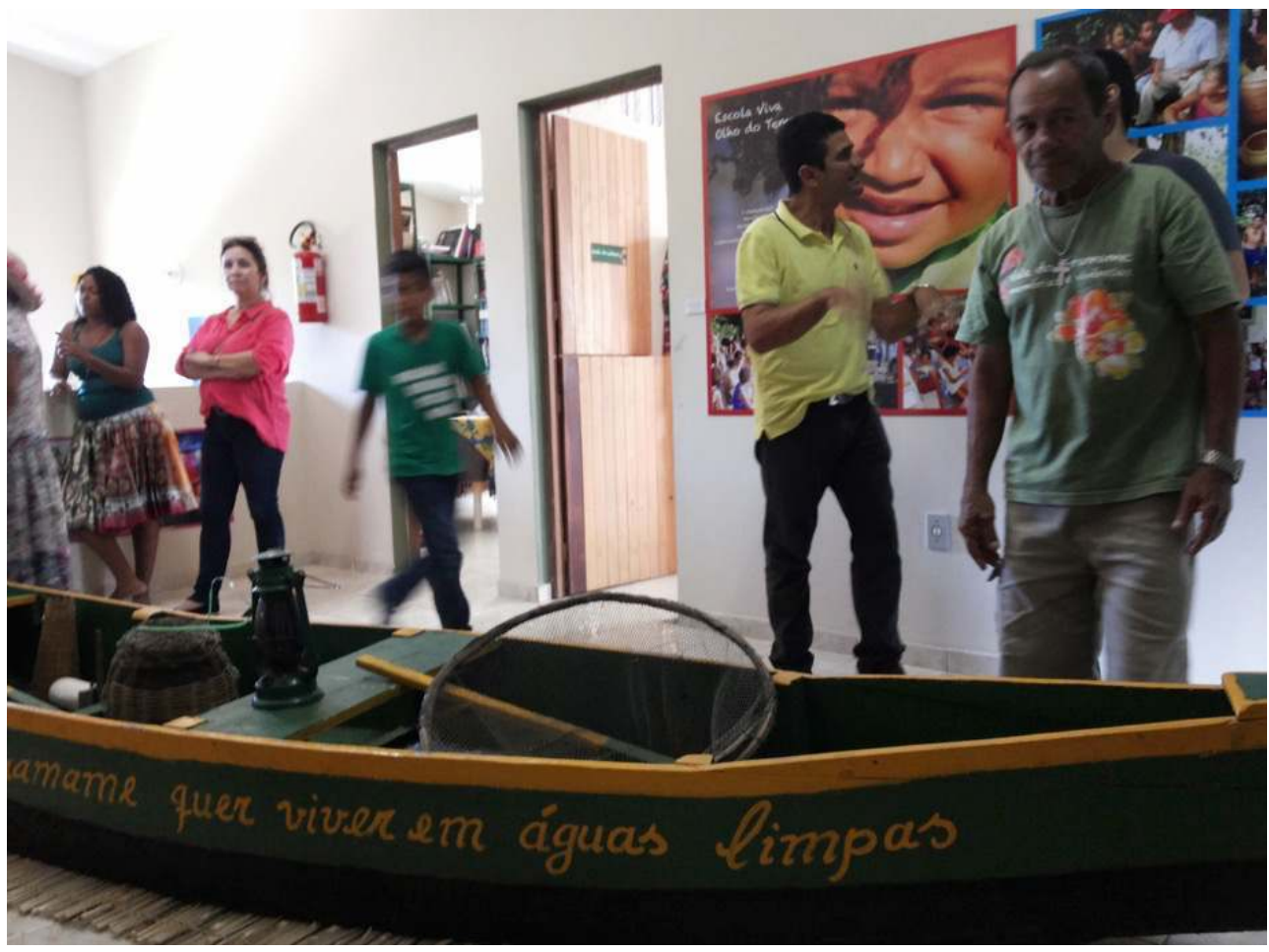

Fig. 3 - Uma das salas da exposição, com barco ao centro

(C) Atila Bezerra Tolentino

Ao longo desta sala, outros objetos e painéis são expostos, cujas imagens remetem para o universo do dia a dia do Vale do Gramame e para as principais festas e manifestações culturais locais, como o banho e a lavagem de roupa no rio, a pesca de camarão, a sumptuosa Ponte dos Arcos, a capoeira, o cultivo da mandioca e a feitura da farinha na casa de farinha comunitária, a caminhada de São José, o São João Rural, etc. Outros painéis são destinados a mostrar os trabalhos desenvolvidos pela EVOT e pelas atividades culturais por esta promovidas, como o Encontro Cultural "O Vale vai às Praças".

$\mathrm{Na}$ outra sala, juntamente com os painéis destinados aos mestres locais, inclui-se a reprodução de uma cozinha rural local, com destaque para o fogão de barro, muito comum nas casas da redondeza (fig. 4). Acima e em redor do fogão, expõe-se uma série de objetos relacionados com o universo da cozinha e com o dia a dia das casas das comunidades, muitos deles produzidos pelos próprios moradores, como os balaios e a cestaria. Por toda a exposição, em vez de textos informativos, são priorizados textos que visam comunicar com o visitante por meio da ludicidade e da poesia. Mais do que informar, a preocupação é sensibilizar e cativar o público. Para isso, são explorados textos de poetas locais, sobretudo da mestra Judite Palhano. 


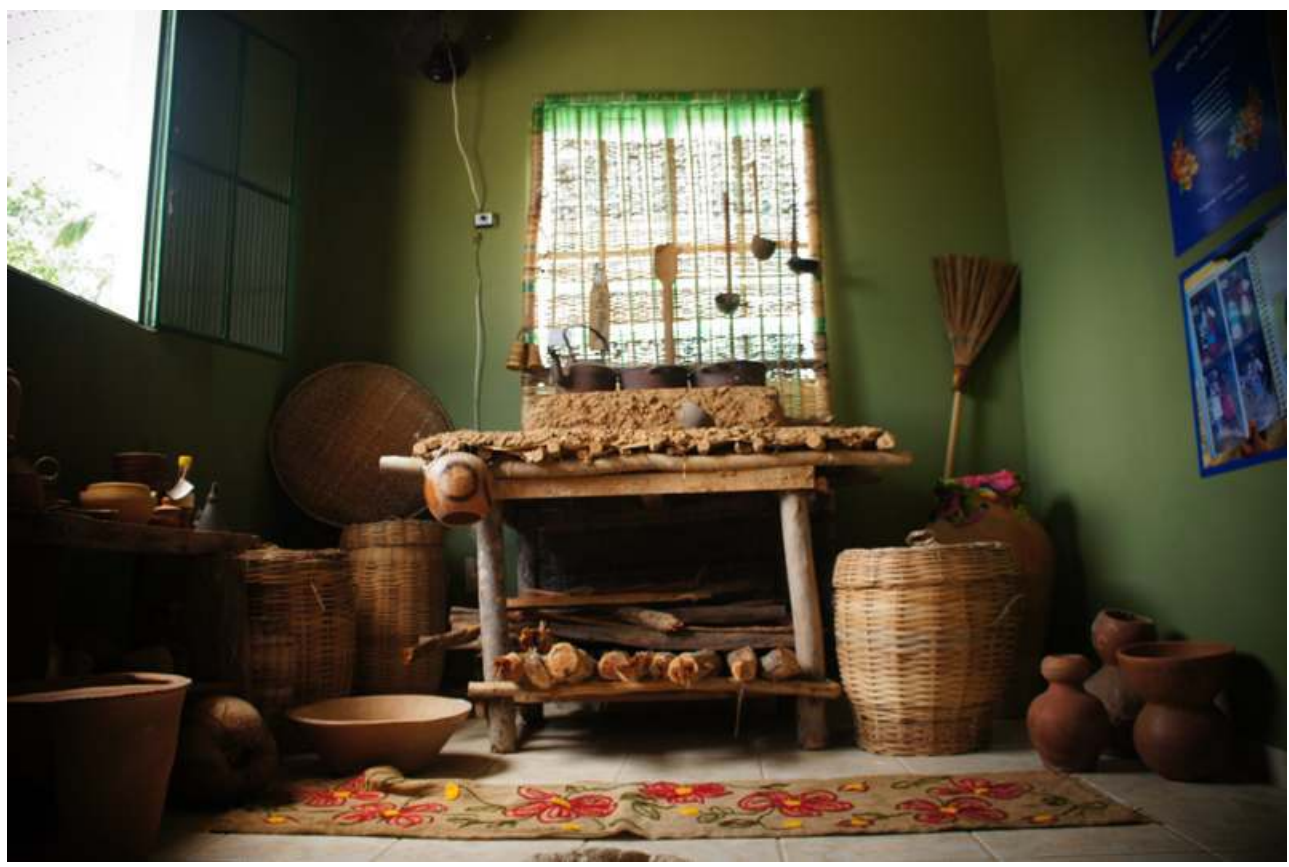

Fig. 4 - Reprodução de cozinha rural no museu, 2014

(c) Moysés Siqueira Neto

O desenho que se vê na expografia do Museu Comunitário da EVOT é o olhar das pessoas das próprias comunidades, que se destacam não por conta de forças económicas, mas pela sua atuação no campo cultural ou pelo trabalho tradicional que desenvolvem. A tessitura do seu circuito expositivo permite considerá-lo como um "museu-narrativa" (Gonçalves 2007), pois está fortemente pautada na poesia e no rigor estético, presentes tanto nos textos utilizados como no discurso construído com os objetos selecionados para exposição. De forma leve e fluida, como as águas do rio, o circuito expositivo segue o seu curso e mostra ao público as belezas naturais e a vivacidade local, como também os problemas sociais do Vale do Gramame.

\section{Construindo patrimónios, memórias e identidades: disputa política, económica e simbólica}

A experiência da montagem do Museu Comunitário da EVOT e da reformulação do seu circuito expositivo serve como espaço de análise do processo de construção e seleção de patrimónios culturais, como também das questões que envolvem as construções de identidade cultural. Os museus, concebidos como espaços de poder (Chagas 2009), legitimam um discurso e, portanto, produzem uma verdade. Hall (2011) também afirma que uma cultura nacional é um discurso, ou seja, um modo de construir sentido que influencia as nossas ações e a conceção de que temos de nós mesmos. Esses sentidos sobre a nação, contidos nas histórias contadas, nas memórias e nas imagens desenhadas, também constroem identidades. Em vez de se pensar as culturas nacionais como unificadas, é necessário pensá-las como "dispositivos discursivos".

Construir a memória coletiva de determinados grupos sociais também é construir um discurso. $\mathrm{O}$ estudo da memória como um fenómeno social ganhou corpo e se instaurou como um campo de pensamento nas ciências sociais no início do século $\mathrm{XX}$, a partir das 
investigações e reflexões do sociólogo francês Maurice Halbwachs, sobretudo nas suas obras Os Contextos Sociais da Memória, de 1925, e A Memória Coletiva, publicada postumamente, em 1950, a partir de papéis deixados pelo autor. Discípulo da Escola sociológica francesa e um rigoroso durkheiminiano, Halbwachs (2006) mostra que a memória só pode ser construída no seio do tecido social e que ninguém pode lembrar-se realmente a não ser em sociedade. Em contraponto com a memória individual, esta é considerada como um ponto de vista sobre a memória coletiva, que muda segundo o lugar ocupado pelos sujeitos sociais e as relações que mantêm. Seguindo o pensamento de E. Durkheim, Halbwachs não dá ênfase aos jogos de disputa e conflitos em torno da construção dessa memória coletiva. Na verdade, a memória coletiva representa os consensos, mesmo que mínimos, ou uma combinação dos conjuntos coletivos que delineiam o bom funcionamento do tecido das relações sociais:

Para que a nossa memória se aproveite da memória dos outros, não basta que estes nos apresentem seus testemunhos: também é preciso que ela não tenha deixado de concordar com as memórias deles e que existam muitos pontos de contato entre uma e outras para que a lembrança que nos fazem recordar venha a ser reconstruída sobre uma base comum. (Halbwachs 2006, 39)

Apesar de a questão dos conflitos sociais não ser ponto central nas investigações halbwachianas, elas serviram de base para uma linha de pensamento da memória como fenómeno social em que vários autores avançaram nas reflexões acerca das disputas e tensões que envolvem a construção coletiva das memórias, como Pierre Nora, Michel Pollak e Jöel Candau. O historiador Paul Ricouer também é um deles. Em instigante reflexão sobre os abusos da memória, e consequentemente do esquecimento, Ricoeur (2007) argumenta que um desses abusos é a memória manipulada, ou seja, formas concertadas de manipulação ou de instrumentalização da memória e de esquecimento pelos detentores de poder. Essa abordagem, acrescenta Ricoeur, está estritamente ligada à questão de a memória estar a serviço da busca e da reivindicação de identidade.

Essa simbiose entre memória e identidade está eivada de fragilidades. A primeira causa dessas fragilidades é a difícil relação da identidade com o tempo, que «justifica o recurso à memória, enquanto componente temporal da identidade, juntamente com a avaliação do presente a projeção do futuro» (Ricouer 2007, 94). A dificuldade da relação com o tempo reside no facto de delimitar o que significa permanecer o mesmo através do tempo. A segunda causa diz respeito ao confronto com os outros, percebido como uma forma de ameaça. $O$ outro é percebido como um perigo para a identidade própria, tanto a coletiva como a pessoal, resvalando numa alteridade mal tolerada. Em vez de acolhida, o que se propaga é a rejeição e a exclusão. A terceira causa é a que Ricouer chama de herança da violência fundadora, isto é, toda a comunidade histórica nasceu de uma relação original com a guerra. Os acontecimentos fundadores, celebrados coletivamente, são actos violentos legitimados por um Estado de direito. É decorrente da segunda causa, pois esses acontecimentos, que significam glória para uns, representam humilhação para outros. Estas fragilidades perpassam os maus usos e os abusos da memória, por meio da manipulação de reivindicações de identidades e expressões públicas da memória. Trata-se do fenómeno da ideologia, explica Ricouer, cujo processo é opaco por constituir-se dissimulado, ou seja, «mascara-se ao se transformar em denúncia contra os adversários no campo da competição entre ideologias» (Ricouer 2007, 95). O fenómeno ideológico também se constitui como uma legitimação de uma ordem ou de um sistema de poder. Recorrendo a Clifford Geertz, defende que esse fenómeno se inscreve na órbita de uma "semiótica da cultura". As distorções da realidade e a legitimação da ordem e do sistema 
de poder dão-se por meio de sistemas simbólicos imanentes à ação, em que a ideologia é tida como "guardiã da identidade, na medida em que esta oferece uma réplica simbólica às causas de fragilidade dessa identidade» (Ricouer 2007, 95-96). E conclui taxativamente: «Definitivamente, a ideologia gira em torno do poder» (Ricouer 2007, 96).

A linha de pensamento de Bourdieu (2005), outro intelectual da Escola sociológica francesa, pautada na questão do poder a partir do capital simbólico, embora não tenha a memória coletiva como tónica, é também importante para refletir sobre a trama que envolve o jogo social da sua construção e representação. No processo de seleção de patrimónios e construção de memórias e identidades - concebido como um espaço social de disputa política, económica e simbólica -, o jogo de construções discursivas tende a reproduzir, como um discurso homogeneizante, a manutenção de uma hegemonia de determinados grupos sociais dominantes, detentores de maior "capital simbólico". Para compreender o conceito de capital simbólico, central no pensamento bourdieusiano, antes faz-se necessário traçar considerações sobre outro conceito fundamental de sua obra, ou seja, a noção de habitus. Para Bourdieu, os atores escolhem estratégias nas suas ações e têm a capacidade de manipulá-las, mas dentro de um quadro limitado da sua experiência social. Essas determinações ou disposições estão dentro de um espaço social concreto, dentro de uma determinada realidade ou, dito de outra forma, as regras das formas sociais vão se incorporando às ações dos agentes sociais. $O$ que existe são formas internalizadas, incorporadas, que se transformam em carne (ou seja, corporificam-se) e condicionam as ações dos indivíduos. O habitus é essa incorporação das estruturas (de valores, regras, etc) pelos indivíduos. A vida social do indivíduo, assim, transforma-se enquanto corpo. Nas palavras de Bourdieu, o habitus é entendido como «um corpo socializado, um corpo estruturado, um corpo que incorporou as estruturas imanentes de um mundo ou de um setor particular desse mundo, de um campo, e que estrutura tanto a percepção desse mundo como a ação desse mundo» (Bourdieu 2005, 144). Nessa perspetiva, Miceli explica:

O habitus seria um conjunto de esquemas implantados desde a primeira educação familiar, e constantemente repostos e reatualizados ao longo da trajetória social restante, que demarcam os limites à consciência possível de ser mobilizada pelos grupos e/ou classes, sendo assim responsáveis, em última instância, pelo campo de sentido em que operam as relações de força. (Miceli 2005, XLII)

Na sua conceção, Bourdieu entende que os processos de diferenciações das funções ao longo da modernidade fizeram com que existissem diferentes campos sociais, além do campo económico. Cada campo, por conta do processo de diferenciação, detém um habitus específico e um "capital" particular, bem como uma disputa por um tipo específico de capital. Isso faz com que cada campo tenha as suas regras, as suas lógicas, numa relação de dominantes (aqueles que detêm mais capital) e de dominados (que necessariamente lutam para adquirir mais capital). Essa lógica de disputa de poder ou de capital é central para o movimento das ações ou das disposições dos agentes sociais. Cada campo produz a sua forma de interesse, que, do ponto de vista do outro campo pode parecer desinteresse. Nesse contexto, Bourdieu traz a sua noção de capital simbólico:

Qualquer tipo de capital (económico, cultural, escolar ou social) percebido de acordo com as categorias de percepção, os princípios de visão e de divisão, os sistemas de classificação, os esquemas classificatórios, os esquemas cognitivos, que são, em parte, produto da incorporação das estruturas objetivas do campo considerado, isto é, da estrutura de distribuição do capital no campo considerado. (Bourdieu 2005, 149) 

Nessa relação de poder, entra necessariamente a questão do capital. Mas diferentemente de Karl Marx, Bourdieu não toma como existente apenas o capital económico e não entende que este é o único motor da relação de poder entre os agentes sociais. 0 poder exerce-se de outras formas. Tantas são as formas de interesse quanto de poder ou, dito de outra forma, Bourdieu considera que existem múltiplos valores na vida social e muitas outras formas de poder. Existem, portanto, diferentes tipos de capital. O capital simbólico é o que conhecemos, detemos e atribuímos valor (nos seus diversos sentidos) nos distintos campos ou universos sociais, onde sempre haverá disputa (numa relação de poder) por esse capital. como os diferentes grupos se apropriam da sua herança cultural e como são regidos os jogos de disputas e as relações de poder em torno da seleção dos patrimónios e da construção das narrativas identitárias. No caso da construção da narrativa do Museu Comunitário da EVOT, podemos considerar que se procurou delinear um discurso em que estivesse presente um património cultural construído e apropriado socialmente, pautado pelas referências culturais locais e não na visão de grupos sociais economicamente hegemónicos.

anclini (1997) aponta que mesmo nos países onde o discurso oficial adota a noção antropológica de cultura, que confere legitimidade a todas as formas de organizar e simbolizar a vida social, existe uma hierarquia dos capitais culturais: a arte vale mais que o artesanato, a medicina científica mais do que a popular, a cultura escrita mais que a transmitida oralmente. A reformulação do património em termos de capital cultural tem a vantagem de não representá-lo como um conjunto de bens estáveis e neutros, com valores e sentidos fixados de uma vez para sempre, mas como um processo social, que, como qualquer outro capital, acumula-se, reestrutura-se, produz rendimentos e é apropriado de maneira desigual por diversos setores.

$\mathrm{Na}$ experiência do Museu Comunitário da EVOT, a lógica hegemónica de seleção e apropriação do património, senão no todo, ao menos em parte reverteu-se. Os patrimónios culturais e a construção identitária do Vale do Gramame, que pautaram a construção do discurso da narrativa expográfica do museu, basearam-se na visão dos mestres e mestras tradicionais locais, considerados como os principais detentores de capital simbólico na região, na perspetiva de portadores de conhecimento, saberes e fazeres e responsáveis pela transmissão oral desse capital. Além disso, a construção coletiva desse património e das suas memórias, ao constituir-se por meio de rodas de conversas entre distintos atores sociais, inclusive por meio da troca intergeracional, beneficiou a apropriação dessa herança cultural e relaciona-a com vida quotidiana desses atores de uma forma global, apontando, inclusive, problemas sociais que impactam diretamente nas suas referências culturais, como o caso da poluição dos rios.

De qualquer modo, concebendo o património cultural e a memória circunscritos num jogo de construção e necessariamente de conflitos sociais, mesmo em espaços democráticos como o demonstrado no Vale do Gramame, algumas memórias continuam subterrâneas (Pollak 1989), ficando no campo do esquecimento, e deixam de ser representadas nas narrativas identitárias construídas. Chamamos a atenção no circuito expositivo do Museu Comunitário da EVOT, a ausência de referências às religiões afrodescendentes, principalmente considerando a existência de comunidades quilombolas na região. Isso 
demonstra como as religiões de matrizes africanas ainda são extremamente estigmatizadas inclusive pelos atores sociais que estão passando por um processo de afirmação das suas identidades, permanecendo ora a reboque de um sincretismo cultural, ora extremamente escondidas, como se a sua prática fosse um crime.

\section{Considerações finais}

Hall (2003), ao abordar a relevância de Antonio Gramsci para o estudo da raça e da etnicidade, aponta que o pensamento do intelectual italiano engloba as novas formas de conceituar os sujeitos da ideologia, recusando um sujeito ideológico unificado e predeterminado. Complementa que «a natureza multifacetada da consciência não é um fenómeno individual, mas coletivo, uma consequência do relacionamento entre 'o eu' e os discursos ideológicos que compõem o terreno cultural da sociedade» (Hall 2003, 324). A pluralidade dos "eus" e das identidades é uma questão crucial na construção dos discursos museológicos e na forma como está espelhada nas narrativas expositivas. Ao assinalar que o campo dos museus atua na campo da memória e do poder, aí encontramse os conflitos sociais que permeiam a luta política, económica e simbólica da constituição dos patrimónios culturais e das narrativas identitárias. Quando falamos de construção de memórias coletivas, patrimonialização e musealização, estão implicados necessariamente o esquecimento e a seleção, e consequentemente o perigo dos abusos da memória e do esquecimento, conforme alertado pelo historiador Paul Ricouer. $O$ esquecimento (ou, por extensão, o vazio, o não dito) e a seleção do que é patrimonializável ou musealizável muito nos dizem da formação de nossa memória coletiva expressa nos discursos museológicos. Procurar antever nas entrelinhas e no invisível o que está no campo do esquecimento ou no processo de seleção do que foi musealizado, dá-nos pistas ${ }^{5} \mathrm{e}$ informações (paradoxalmente contidas nos vazios da falta de informação) de como os sujeitos sociais e as suas memórias são representados e que poder é legitimado nos discursos museológicos.

A nossa memória, como sublinha Halbwachs, «não se apoia na história aprendida, mas na história vivida» (2006, 78-79). Esta afirmação é colocada no contexto em que diferencia a memória coletiva da memória histórica. As duas não se confundem e chega a afirmar que «a expressão memória histórica não é muito feliz, pois associa dois termos que se opõem em mais de um ponto» (Halbwachs 2006, 100). A história só começa, continua o autor, no «momento em que se apaga ou se decompõem a memória social. Enquanto subsiste uma lembrança, é inútil fixá-la por escrito ou pura e simplesmente fixá-la» (Halbwachs 2006, p. 100). Esta reflexão de Halbwachs permite-nos repensar como o património cultural, enquanto algo que supostamente herdamos é constituído e constituidor de memórias coletivas, são efetivamente apropriados pelos sujeitos sociais. Parafraseando o pensador francês, ousaríamos afirmar que o nosso património cultural não é aquele que simplesmente herdamos (como a história aprendida), mas aquele do qual nos apropriamos e construímos socialmente (como a história vivida). Até porque aquilo que se herda, pode-se aceitar ou não, pode-se tomar como nosso ou não. Mas, na medida em que atuamos como sujeitos sociohistóricos da definição e construção do património cultural dos grupos sociais em que estamos inseridos, esse património torna-se parte integrante das nossas referências e constituidor da identidade de cada um.

O museu é o locus da representação dos discursos constituidores desses patrimónios, memórias e identidades. E é, também, na representação desses discursos, o espaço por 
excelência da construção de verdades, na medida em que as verdades não são dadas, mas o resultado de uma construção social em que também estão presentes os conflitos e as relações de forças entre os agentes sociais. As verdades são socializadas e absorvidas, portanto podem criar sujeitos, por meio da subjetivação, sempre permeada por critérios ideológico-políticos e pelas relações de poder (Tolentino, 2014). o discurso museológico, ao constituir-se uma síntese dos patrimónios, das memórias e das identidades de uma coletividade, legitima uma verdade que empodera determinados grupos sociais e pode subjugar outros. É, por isso, alerta Chagas (2009), que os museus podem libertar e aprisionar.

O espírito da dança klassila, do povo kwagiulth, conseguiu entrar na morada sagrada dos museus para produzir o seu discurso e assumi-lo como um espaço de liberdade e emancipação. As comunidades do Vale do Gramame também encontraram no espaço museal a possibilidade de serem sujeitos e construtores da sua própria narrativa, concebendo e ressignificando esse locus sagrado, tornando-o reflexo e síntese de uma experiência de constituição de patrimónios culturais, identidades e memórias, baseada em referências culturais locais e com a participação coletiva dos agentes sociais, produtores e detentores dessas referências.

\section{BIBLIOGRAFIA}

Abreu, Regina Maria do Rego Monteiro. 2007. "Património Cultural: Tensões e Disputas no Contexto de uma Nova Ordem Discursiva." In Antropologia e Patrimônio Cultural: Diálogos e Desafios Contemporâneos, organizado por Manuel Ferreira Lima Filho, Cornelia Eckert e Jane Beltrão, 263-285. Blumenau: Nova Letra.

Barrera, Mabel García. 2006. "El Discurso Poético Mapuche y su Vinculación con lós ‘Temas de Resistência Cultural'." Revista Chilena de Literatura 68: 169-197.

Bourdieu, Pierre. 2005. Razões Práticas: Sobre a Teoria da Ação. 7. ed. Campinas: Papirus.

Castells, Manuel. 2008. O Poder da Identidade: A Era da Informação: Economia, Sociedade e Cultura. 6. ed. São Paulo: Paz e Terra.

Chagas, Mário de Souza. 2009. A Imaginação Museal: Museu, Memória e Poder em Gustavo Barroso, Gilberto Freyre e Darcy Ribeiro. Brasília: Ministério da Cultura, Instituto Brasileiro de Museus.

Clifford, James. 2003. "Museologia e Contra-história: Viagens pela Costa Noroeste dos Estados Unidos.” In Memória e Patrimônio: Ensaios Contemporâneos, organizado por Cláudia Dias, Regina Abreu, Mário de Souza Chagas, 255-302. Rio de Janeiro: DP\&A.

García Canclini, Nestor. 1997. Culturas Híbridas: Estratégias para Entrar e Sair da Modernidade. São Paulo: Editora da Universidade de São Paulo.

García Canclini, Nestor. 1999. "Los Usos Sociales del Patrimonio Cultural.” In Patrimonio Etnológico: Nuevas Perspectivas de Estudio, organizado por Encarnación Aguiar Criado, 16-33. [Sevilha]: Instituto Andaluz del Patrimonio Histórico. 
Ginzburg, Carlo. 1989. Mitos, Emblemas e Sinais: Morfologia e História. Tradução de Frederico Carotti. São Paulo: Companhia das Letras.

Gonçalves, José Reginaldo Santos. 2003. “O Patrimônio como Categoria de Pensamento.” In Memória e Patrimônio: Ensaios Contemporâneos, organizado por Cláudia Dias, Regina Abreu, Mário de Souza Chagas, 21-29. Rio de Janeiro: DP\&A.

Gonçalves, José Reginaldo Santos. 2007. “Os Limites do Patrimônio.” In Antropologia e Patrimônio Cultural: Diálogos e Desafios Contemporâneos, organizado por Manuel Ferreira Lima Filho, Cornelia Eckert e Jane Beltrão, 239-248. Blumenau: Nova Letra.

Halbwachs, Maurice. 2006. A Memória Coletiva. 1. ed. São Paulo: Centauro.

Hall, Stuart. 2003. Da Diáspora: Identidades e Mediações Culturais. Organização de Liv Sovik. Belo Horizonte: Universidade Federal de Minas Gerais.

Hall, Stuart. 2011. A Identidade Cultural na Pós-modernidade. 11.a ed. Rio de Janeiro: DP\&A.

Miceli, Sergio. 2005. "Introdução: A Força do Sentido. In A Economia das Trocas Simbólicas, de Pierre Bourdieu, VII-XLI. 6. e․ São Paulo: Perspectiva.

Pollak, Michael. 1989. “Memória, Esquecimento, Silêncio.” Estudos Históricos. 2 (3): 3-15.

Ricouer, Paul. 2007. A Memória, a História, o Esquecimento. Campinas: Editora da Unicamp

(Universidade Estadual de Campinas).

Tolentino, Átila Bezerra. 2014. “Entre Políticos e Mestres da Cultura Popular: Discurso, Poder e Ideologia nos Museus.” Cadernos de Sociomuseologia 47 (3): 43-70.

Whyte, Willian Foote. 1980. “Treinando a Observação Participante: Desvendando as Máscaras Sociais.” In Desvendando as Máscaras Sociais, organizado por Alba Zaluar Guimarães, 77-86. 2. ed. Rio de Janeiro: Francisco Alves Editora.

\section{NOTAS}

1. Barrera (2006) explica que resistência cultural foi o termo acertadamente usado por Edward Said no seu livro Cultura e Imperialismo, referindo-se às atividades, reflexões e revisões anticolonialistas, que atualmente os povos "subordinados" realizam sobre o devir da sua história e as condições de imposição a que foram submetidos, invertendo, assim, o relato que se legitimou na história oficial de dominação, exigindo dos povos ocidentais que se vejam a si mesmos como representantes de culturas, incluindo raças submetidas a repressão, violência e crimes de consciência.

2. Trata-se de uma Organização da Sociedade Civil de Interesse Público (OSCIP).

3. A conceção de museu, quando tratamos sobretudo, de museus comunitários e ecomuseus, é bastante ampla e não está restrita a uma exposição em quatro paredes. Não é diferente no caso do Museu Comunitário da EVOT, em que os espaços museais abarcam toda a região da escola e o seu entorno, inclusive uma grande área verde de Mata Atlântica onde são realizadas as ações de educação ambiental. No entanto, este artigo analisa a narrativa do espaço expositivo do museu disposto em duas salas da escola.

4. Gonçalves (2007) faz a distinção entre «museu-informação» e «museu-narrativa» a partir das premissas expostas no famoso ensaio 0 Narrador, de Walter Benjamin. 0 museu-narrativa, assim, surge em contexto urbano no qual a relação com o público ainda guarda uma marca pessoal e desencadeia a fantasia do visitante, uma vez que não está amarrado a qualquer informação definida. Esses museus «configuram um espaço propício à flânerie» (p. 71). Os museus- 
informação, por sua vez, «desenvolvem-se em função das grandes metrópoles e de suas multidões anônimas, definindo-se a partir de suas relações com o mercado, com um vasto público voltado para o consumo de informações e bens culturais» (p. 72).

5. Neste contexto tem-se em consideração o paradigma indiciário proposto pelo historiador italiano Carlo Ginzburg (1989), em que o método interpretativo deve ser baseado nos dados marginais, nos resíduos ou indícios, considerados reveladores.

\section{RESUMOS}

Ao compreender que a área do património cultural se constitui como um espaço social de disputa política, económica e simbólica, este artigo pretende identificar e refletir de que forma a diversidade cultural e as memórias coletivas das comunidades do Vale do Gramame (Estado de Paraíba, Brasil), são representadas na narrativa expositiva do Museu Comunitário da Escola Viva Olho do Tempo. O debate leva em consideração as discussões já travadas por autores que tratam o património cultural como categoria do pensamento, bem como questões apontadas por Stuart Hall a respeito da construção das identidades culturais na modernidade, a constituição da memória como um elemento social, a partir de Maurice Halbwachs e Paul Ricouer, e as relações de força que envolvem a conceção de capital simbólico proposto por Pierre Bourdieu. Além da pesquisa teórica, o trabalho pautou-se pela observação participante durante o trabalho de campo, ocorrido entre 2014 e 2015. Como resultado, propõe-se que os museus são espaços constituídos de poder e de empoderamento. Em função disso, novos sujeitos e grupos sociais, como as comunidades do Vale do Gramame, comummente não representadas ou silenciadas nesses espaços, estão a apropriar-se dos museus para que incluam as suas memórias e identidades.

By understanding that the cultural heritage is constituted as a social space for political, economic and symbolic dispute, this article aims to identify and reflect how the cultural diversity and the collective memories of Gramame Valley communities (Paraíba, Brazil) are represented in the exhibition narrative of the Escola Viva Olho do Tempo Community Museum. The debate takes into account ideas already discussed by authors dealing with the cultural heritage as a category of thought, as well as issues raised by Stuart Hall about the construction of cultural identity in modernity, the creation of memory as a social element, from Maurice Halbwachs and Paul Ricouer, and the power relations that involve the idea of symbolic capital proposed by Pierre Bourdieu. In addition to the theoretical research, this work was based on participant observation during the fieldwork, which took place between 2014 and 2015. As a result, it is proposed that museums are spaces made up of power and empowerment. Thus, new subjects and social groups such as the communities of Gramame Valley, commonly unrepresented or silenced in these spaces, are taking ownership of museums to conform their memories and identities.

\section{ÍNDICE}

Keywords: cultural heritage, intangible cultural heritage, social museology, memory, identity Palavras-chave: património cultural, património cultural imaterial, museologia social, memória, identidade 


\section{AUTOR}

\section{ATILA BEZERRA TOLENTINO}

Graduado em Letras Português pela Universidade de Brasília (1997), com especialização em Políticas Públicas e Gestão Governamental pela Escola Nacional de Administração Pública (1999) e em Gestão de Políticas Públicas de Cultura pela Universidade de Brasília (2008). Mestre em Sociologia na Universidade Federal da Paraíba. Pertence à carreira de Especialista em Políticas Públicas e Gestão Governamental do Ministério do Planejamento, Orçamento e Gestão, com atuação no Instituto do Patrimônio Histórico e Artístico Nacional (IPHAN) do Ministério da Cultura do Brasil. Coordena as atividades da Casa do Patrimônio da Paraíba, programa de educação patrimonial vinculado à Superintendência do IPHAN no Estado de Paraíba.

atilabt@gmail.com 